\title{
Structure-activity relationship studies of the phytotoxic properties of the diterpenic moiety of breviones
}

\author{
Ceferino Carrera, ${ }^{\text {a Nuria Chinchilla, }}{ }^{\text {a }}$ Frank R Fronczek, ${ }^{b}$ Juan CG Galindo ${ }^{\text {a }}$ \\ and Francisco A Macías ${ }^{\mathrm{a}^{*}}$
}

\begin{abstract}
BACKGROUND: Brevianes are a family of bioactive meroterpenoids originally described in fungi of the family Penicillium. These compounds have attracted a great deal of interest not only because of their unusual skeleton, suggesting a mixed mevalonate and polyketide biogenetic pathway, and their unusual oxa-spiro ring fused to an $\alpha$-pyrone, but also because of the bioactivities shown by many members of this family.
\end{abstract}

RESULTS: During the course of a project aimed at the total synthesis of natural breviones $\mathrm{A}$ to $\mathrm{E}$, the authors were able to synthesise the diterpenic moiety of brevianes and abeo-brevianes. As a result, a collection of 25 compounds were synthesised and tested for bioactivity by two different bioassays. The bioassays used were etiolated wheat coleoptiles (Triticum aestivum) and seedlings in petri dishes. The plant species tested in the seedling bioassay were the commercial dicots lettuce and cress and the monocot weeds Echinochloa crus-galli and Lolium rigidum.

CONCLUSIONS: The results clearly show that expanded phenanthrene-like compounds corresponding to the diterpenic moiety of abeo-brevianes are more selective towards $E$. crus-galli in comparison with $L$. rigidum. Such selectivity can reach up to one order of magnitude (200-fold) and makes some of the compounds good candidates as leads for the development of more specific herbicides.

(c) 2014 Society of Chemical Industry

Supporting information may be found in the online version of this article.

Keywords: breviones; diterpenes; herbicides; structure-activity relationship

\section{INTRODUCTION}

Pesticide research is challenged by the urgent need to develop effective new pest control methods that are both safe to humans and environmentally friendly. These new methods also face acceptance by a society that is increasingly reluctant to use pesticides. Natural products represent an important alternative, not only because of their enormous structural diversity but also for their wide spectrum of biological activities. ${ }^{1}$ In those cases where they are naturally or synthetically available at a multigram scale, such compounds are excellent candidates to be used as agrochemicals.

Fungi are excellent sources of fungitoxins. Penicillium, Aspergillus and Fusarium are well-known fungus genera producing metabolites of high toxicity. Among them, Penicillium brevicompactum var. brevicompactum Dierckx is described as one of the more prolific. ${ }^{2}$ Compounds isolated from $P$. brevicompactum present a great diversity of biological properties, which include activities such as antijuvenile hormone $\mathrm{s}^{3-5}$ and inhibition of the mitochondrial respiratory chain: ${ }^{6} \mathrm{~N}$-(2-methyl-oxodecanoyl)-2-pyrrolidine (1) and brevioxime (2) are reported to be insecticidal, while brevicompanins $A(3), B(4)$ and $C(5)$ are growth regulators ${ }^{7,8}$ and adenophostins $A(6)$ and $B(7)$ are reported to be potent receptor antagonists of D-myo-inositol-1,4,5-triphosphate (Fig. 1)., 9,10
Breviones are a family of metabolites originally isolated from the fungus $P$. brevicompactum. They are characterised by a new skeleton named breviane. To date, three possible structural alternatives have been characterised: brevianes, abeo-brevianes and nor-abeo-brevianes (Fig. 2). ${ }^{11,12}$ The first compounds reported from $P$. brevicompactum were breviones $A$ to $E$ ( 8 to 12 ), followed by breviones $\mathrm{F}$ to $\mathrm{H}(\mathbf{1 3} \text { to } \mathbf{1 5})^{13}$ and breviones I to $\mathrm{K}$ (16 to $\left.\mathbf{1 8}\right),{ }^{14}$ which were isolated from a Penicillium spp. strand extracted from samples of deep seafloor sediments collected at $5115 \mathrm{~m}$ depth in the eastern Pacific Ocean (Fig. 3).

Brevianes are meroterpenes consisting of a phenanthrene core with methyl groups at positions $\mathrm{C} 4, \mathrm{C} 8, \mathrm{C} 10$ and $\mathrm{C} 13$ with

\footnotetext{
Correspondence to: Francisco A Macías, Department of Organic Chemistry, School of Sciences, University of Cádiz, C/República Saharaui, s/n, 11510 Puerto Real, Cádiz, Spain.E-mail: famacias@uca.es

a Grupo de Alelopatía, Departamento de Química Orgánica, Facultad de Ciencias, Instituto de Biomoléculas (INBIO), Universidad de Cádiz, Campus de Excelencia Internacional Agroalimentario (ceiA3), Spain

b Department of Chemistry, Louisiana State University, Baton Rouge, LA 70803-1804, USA
} 


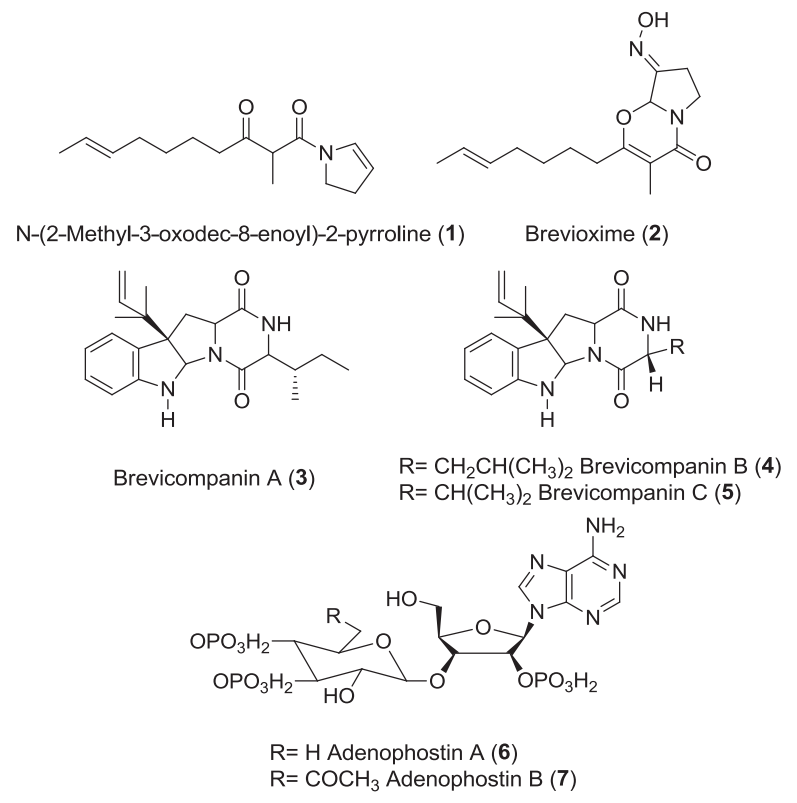

Figure 1. Bioactive compounds isolated from P. brevicompactum.

a defined stereochemistry at positions $\mathrm{C} 8$ and $\mathrm{C} 10$. A mixed biosynthetic origin has been proposed for meroterpenes. ${ }^{15}$ In the case of the merosesquiterpenoids pyripyropenes, the western half of the molecule is proposed to come from the mevalonate pathway. ${ }^{16,17}$ This unit is attached to the pyrone half through a spiro ring junction at carbon $\mathrm{C} 15$ with an $\mathrm{S}$ stereochemistry, which is proposed to arise from condensation of two acetate units with nicotinic acid. ${ }^{16} \mathrm{~A}$ similar combination of mevalonate and acetate pathways has also been proposed for brevianes. ${ }^{18}$ $3(4 \rightarrow 18)$-Abeo-breviane (breviones $\mathrm{C}$, $\mathrm{D}$ and $\mathrm{F}$ to $\mathrm{H}$ ) are distinctive in that ring $A$ is expanded to a seven-membered ring. The cleavage of the $\mathrm{C} 3-\mathrm{C} 4$ bond, followed by rearrangement of the C18 methyl group, should render the expanded ring in the biogenetic pathway. ${ }^{18} 3(4 \rightarrow 18)$-Abeo-1'-nor-brevianes lack the carbonyl group at $\mathrm{C}^{\prime}{ }^{\prime}$ and also present an expanded oxepane ring instead of the pyrone moiety.

Besides their unique structure, breviones are also characterised by their phytotoxicity [breviones E (12) and C (10)], ${ }^{11}$ cytotoxity [breviones $\mathrm{F}$ to $\mathrm{H}$ (13 to $\mathbf{1 5}$ )] and anti-HIV-1 ${ }^{13}$ activity [breviones $\mathrm{A}(\mathbf{8})$ and I (16)]. ${ }^{14}$

In view of the great potential of these compounds, the authors have undertaken the synthesis of brevione and abeo-brevione analogues, starting in the first phase with their western half. ${ }^{19}$ The present paper sets out the results of a structure-activity relationship (SAR) study with 25 compounds having a decalin (19 to 22), saturated phenanthrene-like (23 to $\mathbf{3 4}$ ) and expanded phenanthrene-like (35 to $\mathbf{4 3}$ ) backbone (Fig. 4). Compounds were tested for phytotoxicity using a wheat coleoptile bioassay and a seedling bioassay in petri dishes with commercial crops of lettuce (Lactuca sativa L.) and cress (Lepidium sativum L.) and weed (Lolium rigidum and Echinochloa crus-galli) seeds.

\section{EXPERIMENTAL METHODS}

\subsection{General experimental procedures}

The purity of all compounds was determined by ${ }^{1} \mathrm{H}$ NMR and HPLC analyses and was found to be in all cases $>98 \%$. ${ }^{1} \mathrm{H}$ and ${ }^{13} \mathrm{C}$ NMR spectra were recorded using $\mathrm{CDCl}_{3}$ as solvent on an INOVA spectrometer (Varian Inc., Palo Alto, CA) at 399.99 and $100.577 \mathrm{MHz}$ respectively. The resonance of residual chloroform was set to $\delta 7.25$ ppm for ${ }^{1} \mathrm{H}$ and to $\delta 77.00$ for ${ }^{13} \mathrm{C}$. UV-vis spectra were obtained using a Cary $50 \mathrm{BIO}$ spectrophotometer (Varian Inc.), with chloroform as the solvent. Mass spectra (EIMS) were recorded using a Voyager spectrometer (Thermoquest, Manchester, UK). FTIR spectra were obtained on a Spectrum BX FTIR system (PerkinElmer, Waltham, MA). Frequency values are given in $\mathrm{cm}^{-1}$.

\subsection{Preparation of derivatives}

Decaline compounds 19 to 22 , phenanthrenes 25 to 29 and expanded phenanthrenes $\mathbf{3 5}$ to $\mathbf{4 3}$ were obtained according to Macias et al., ${ }^{19}$ while compounds $\mathbf{3 0}$ to $\mathbf{3 4}$ were obtained according to the methodology previously described by Takikawa et al. ${ }^{20}$ and Yokoe et al. ${ }^{21}$ Classical Robinson annulation of compound (-)-20 leads to $( \pm)-\mathbf{2 3}$ and ( \pm )-24. Supplementary NMR and X-ray data of compound ( \pm )-24 (Fig. 5) can be found in the supporting information. X-ray data in CIF format can also be obtained free of charge from The Cambridge Crystallographic Data Centre, CCDC 953081.

To obtain (4aS,8R,8aR)-8-hydroxy-1,4a,8a-trimethyl-4,4a,6,7,8,8a, 9,10-octahydrophenanthren-2(3H)-one (23), ethyl vinyl ketone
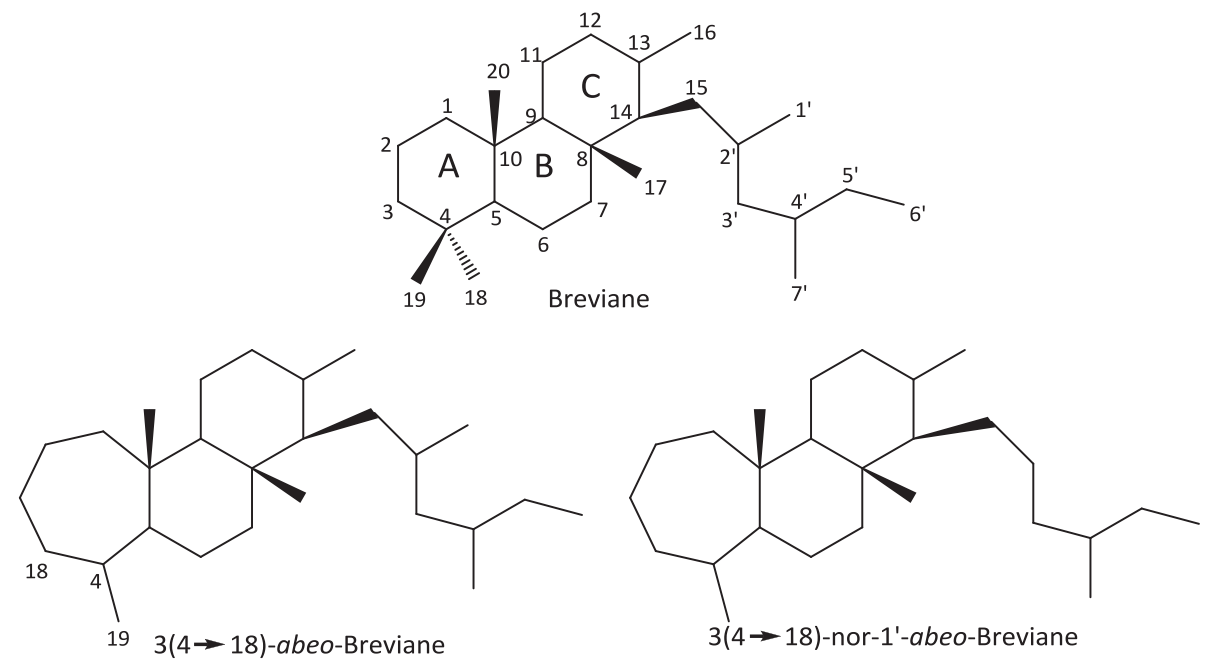

Figure 2. Basic breviane skeletons. 

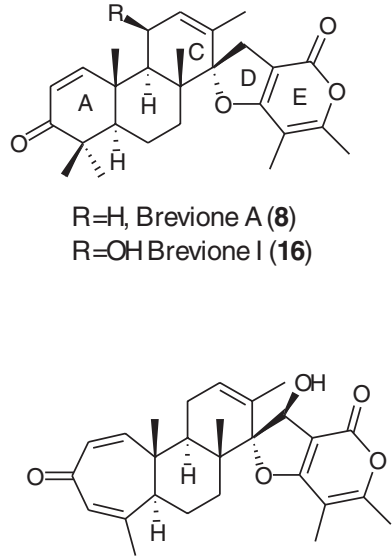

Brevione D (11)

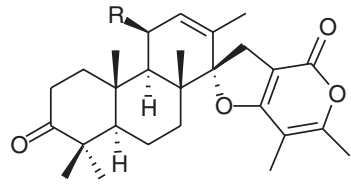

$\mathrm{R}=\mathrm{H}$, Brevione $\mathrm{B}(9)$

$\mathrm{R}=\mathrm{OH}$ Brevione $\mathrm{J}(\mathbf{1 7})$

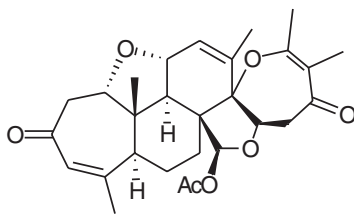

Brevione $\mathrm{E}(\mathbf{1 2})$

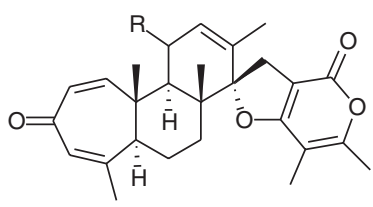

$\mathrm{R}=\mathrm{H}$, Brevione $\mathrm{C}(\mathbf{1 0})$

$\mathrm{R}=\beta \mathrm{OH}$, Brevione $\mathrm{F}(\mathbf{1 3})$

$\mathrm{R}=\alpha \mathrm{OH}$, Brevione $\mathrm{G}(\mathbf{1 4})$

$\mathrm{R}=\mathrm{O}$, Brevione $\mathrm{K}(\mathbf{1 8})$

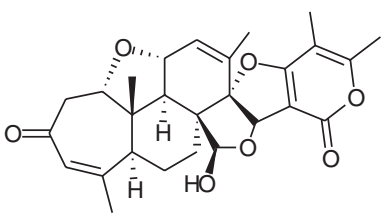

Brevione $\mathrm{H}(\mathbf{1 5})$

Figure 3. Breviones isolated from Penicillium spp.

(EVK) $(7.3 \mathrm{mmol})$ was added to $100 \mathrm{~mL}$ of a $10 \% \mathrm{KOH} / \mathrm{MeOH}$ solution at $-10{ }^{\circ} \mathrm{C}$. Then, $6.6 \mathrm{mmol}$ of a methanolic solution of (-)-20 was added dropwise, and the temperature was allowed to reach room temperature over a $3 \mathrm{~h}$ period. Then, the solution was refluxed for another additional $7 \mathrm{~h}$. The reaction was stopped by adding $0.1 \mathrm{~N} \mathrm{HCl}$, and the methanol was evaporated under vacuum. The aqueous solution was extracted using ethyl acetate $(3 \times)$, and the combined organic phases were dried over anhydrous sodium sulphate and concentrated under vacuum. The reaction crude was purified by CC (Hx:EtOAc 7:3 v/v) and preparative chromatography to render enantiomerically pure $\mathbf{2 3}$ (52\%, 83\% ee) and $40 \%$ of starting material.

The change in the order of the addition of the reactants made it possible to overcome the retroaldolic reaction of compound (-)-20 described by Honda. ${ }^{22}$ The dropwise addition of (-)-20 over the EVK solution in $\mathrm{KOH} / \mathrm{MeOH}$ prevented the base from undergoing the undesired retroaldolic reaction. This is the first report of direct enantioselective synthesis of compound (+)-23.

\subsection{Calculation of $I C_{50}$ and $\log P$}

Data from wheat coleoptile and petri dish seedling bioassays were fitted to a sigmoidal dose-response model (constant slope), whenever possible, using the GraphPad Prism v.4.00 software package (GraphPad Software Inc., San Diego, CA). ${ }^{23}$ Calculated $\log P$ values were obtained using OSIRIS property explorer (Actelion, Allschwil, Switzerland), ${ }^{24}$ which uses the Chou and Jurs algorithm based on computed atom contributions. ${ }^{25}$

\subsection{Biological activity}

\subsubsection{Wheat coleoptile bioassays}

Wheat seeds (Triticum aestivum L. cv. Catervo) were sown in 15 $\mathrm{cm}$ diameter petri dishes moistened with water and grown in the dark at $22 \pm 1{ }^{\circ} \mathrm{C}$ for 3 days. ${ }^{26}$ The roots and caryopses were removed from the shoots and placed in a Van der Weij guillotine. The apical $2 \mathrm{~mm}$ was cut off and discarded. The next $4 \mathrm{~mm}$ of the coleoptiles was removed and used for bioassay. All manipulations were performed under a green safelight. ${ }^{27}$ Test solutions of each compound were prepared in a phosphate-citrate buffer solution containing $2 \%$ sucrose adjusted to $\mathrm{pH} 5.6$ at 1000,333 , 100,33 and $10 \mu \mathrm{M}$. Parallel controls were also run. Five coleoptiles were placed in each test tube containing $2 \mathrm{~mL}$ of test or control solutions ( $2 \mathrm{~mL}$ ) (three replicates per dilution). The test tubes were kept in constant rotation at $0.25 \mathrm{rpm}$ in a roller tube apparatus for $24 \mathrm{~h}$ at $22^{\circ} \mathrm{C}$ in the dark. The coleoptiles were then digitally photographed and measured. Data were statistically analysed using Welch's test. ${ }^{28}$ Results are presented as percentage differences from the control. Thus, zero represents the control, positive values represent growth stimulation and negative values represent growth inhibition. As brevianes are metabolites of fungal origin, mycophenolic acid (MPA) was used as a positive control because of its antifungal activity, ${ }^{29,30}$ aiming to compare the phytotoxicity of this part of the breviane molecules with the activity of a known fungitoxin.

\subsubsection{Seedling bioassays}

Crop seeds of the monocot Lepidium sativum L. (garden cress) and the dicot Lactuca sativa L. cv. Longifolia (romaine lettuce), along with weed seeds of Lolium rigidum Gaud. (rigid ryegrass) and Echinochloa crus-galli (L.) Beauv. were used.

Fifteen seeds per species were placed in $50 \mathrm{~mm}$ diameter petri dishes fitted with Whatman No. 1 filter paper and moistened with $1 \mathrm{~mL}$ of an aqueous solution buffered at pH 6.0 using $10^{-2} \mathrm{M}$ of 2-[N-morpholino]ethanesulfonic acid (MES) and adjusted with $1 \mathrm{M}$ of $\mathrm{NaOH}$. Compound stock solutions were prepared in DMSO (200 $\mathrm{mM}$ ) and then diluted with the buffer to give the appropriate test concentrations (1000,333, 100, 33 and $10 \mu \mathrm{M}$ and $0.5 \% \mathrm{v} / \mathrm{v}$ final concentration of DMSO). Four replicates were set for each solution and test compound. Parallel and positive controls were also run: the commercial herbicides Logran ${ }^{\circledR}$ in the case of crop seeds and Cotanil- $35^{\circledR}$ for weed seeds.

Petri dishes were sealed with parafilm to ensure closed-system models and were incubated at $25^{\circ} \mathrm{C}$ in a Memmert ICE 700 controlled-environment growth chamber in the absence of light. Bioassays took 4 days for cress and rigid ryegrass and 5 days for lettuce and E. crus-galli. After this time, seedlings were frozen at $-10^{\circ} \mathrm{C}$ for $24 \mathrm{~h}$ to stop growth. Automated data recording, analysis and statistics on germination rate, root and shoot length were performed using a Fitomed ${ }^{\odot}$ system. $^{31}$

\subsection{Statistical analysis}

Data were statistically analysed using Welch's test, with significance fixed at 0.01 and 0.05 . Results are represented in bar charts 
Micophenolic acid<smiles>COc1c(C)c2c(c(O)c1C/C=C(\C)CC(=O)O)C(=O)OC2</smiles><smiles>CC1=C2CCCC(=O)[C@@]2(C)CCC1=O</smiles>

$(-)-(19)$

\section{Compounds with decalin skeleton}<smiles>CC1=C2CCC[C@@H](O)[C@]2(C)CCC1=O</smiles>

(-)-(20)<smiles>CC1C(=O)CC[C@@H]2[C@@H](O)CCC[C@H]12</smiles>

(-)-(21)<smiles>C[C@H]1C(=O)CC[C@@]2(O)CCCC[C@H]12</smiles>

$(-)-(22)$

Compounds with phenanthrene-like skeleton (Phs)<smiles>CC1=CCCC2C3(C)CCC(=O)C(C)=C3CCC12O</smiles>

(+)-(23)<smiles>CC1=C2CCC3(C)C(=CCC[C@@H]3O)C2(C)CCC1=O</smiles>

(士)-(24)<smiles>CC12CCC(=O)C[C@H]1CCC1(O)CCCC=C12</smiles>

$(+)-(25)$<smiles>CC12CCCC3(O)C4CCCCC4(C)C13CCC(=O)C2</smiles>

(+)-(26)

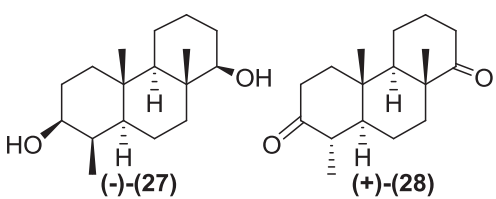<smiles>CO[C@H]1CCC[C@@H]2[C@@H]1CC[C@H]1[C@H]2CC[C@H]2CC(=O)CC[C@@]21C</smiles>

$(+)-(29)$<smiles>CC1C(=O)CCC2(C)C3=CCCC(O)C3CCC12</smiles><smiles>CC1C(=O)CCC2(C)C1CCC1C(O)CCCC12</smiles>

$(+)-(31)$<smiles>CC1C2CCC3(OCCO3)C2CCC2(O)CCCCC12</smiles>

(-)-(32)<smiles>CC12CCCC(=O)C1CCC1C3(CCC12C)OCCO3</smiles>

(-)-(33)

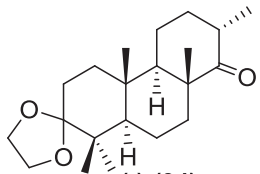

(-)-(34)

Compounds with expanded phenanthrene-like skeleton (ePhs)<smiles>CO[C@H]1CCC[C@H]2[C@@]3(C)CC=CC(=O)[C@H](C)[C@@H]3CC[C@@]12C</smiles>

(+)-(35)

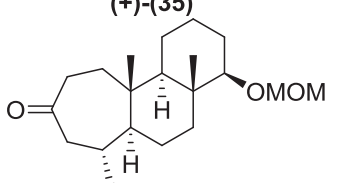

(+)-(38)<smiles>C[C@@H]1CC2(CC[C@@]3(C)[C@@H](O)CCC[C@H]13)OCCO2</smiles>

$(-)-(41)$<smiles>COC1CCCC2C1CCC1C(C)=CC(=O)CCC12C</smiles>

(+)-(36)<smiles>CC1C(=O)CCCC2(C)C1CCC1(O)CCCC12</smiles>

(+)-(39)<smiles>CC12CCC3(CCC1CCC1CCC(=O)CC13)OCCO2</smiles>

(-)-(42)<smiles></smiles>

(+)-(37)<smiles>CC12CCCCC1C1(C)CCC(=O)CC[C@@H]1C2</smiles>

$(+)-(40)$

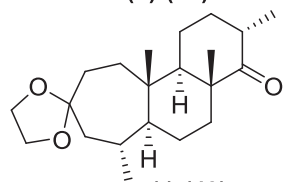

$(-)-(43)$

Figure 4. Compounds tested.

(see the supporting information) as percentages of the control, as described previously. IC $C_{50}$ values were obtained using the GraphPad Prism software v.4.00 (GraphPad Software Inc.). ${ }^{23}$ Complete linkage cluster analysis was based on squared Euclidean distances. The cluster was obtained using Statistica v.5.0 software (Statsoft Inc., Tulsa, OK). ${ }^{32}$

\section{RESULTS AND DISCUSSION}

\subsection{Wheat coleoptile bioassay}

The compounds tested are depicted in Fig. 4, and the overall results are given in Fig. 6 . There is a clear difference between compounds having a decalin backbone and the rest. Decalins 19 to $\mathbf{2 2}$ showed only weak inhibitory activity at $1 \mathrm{mM}$, and they became stimulatory in all cases at concentrations below $100 \mu \mathrm{M}$. The trans-decalin $\mathbf{2 2}$ showed the highest activity (40\% inhibition) in comparison with the other three compounds, which had a cis-decalin (21) or an unsaturated bridgehead carbon $(\mathbf{1 9}, \mathbf{2 0})$ structure.

Saturated phenanthrene-like (23 to $\mathbf{3 4}$ ) and expanded phenanthrene-like (35 to 43 ) compounds were all strongly inhibitory. Most of these compounds showed growth inhibitions in the coleoptiles of between 80 and $100 \%$ at $1 \mathrm{mM}$, with the exception of 33, 34, 42 and $\mathbf{4 3}$. Generally, expanded phenanthrenes were more active, as observed from their activities at $333 \mu \mathrm{M}$ (Fig. 6) and their $\mathrm{IC}_{50}$ values. The saturated phenanthrene-like compounds that showed the highest activities were compounds 23, 29, 31 and 32: 80\% inhibition at 333 $\mu \mathrm{M}$ and an $\mathrm{IC}_{50}$ value below $100 \mu \mathrm{M}$. The most active expanded phenanthrene-like compounds were $\mathbf{3 5}$ and $\mathbf{3 6}$ (80\% inhibition, $100 \mu \mathrm{M})$, followed by 38 and 39 (90\% inhibition, $333 \mu \mathrm{M})$. In all cases, the $\mathrm{IC}_{50}$ values were below 100 and $50 \mu \mathrm{M}$ for saturated 


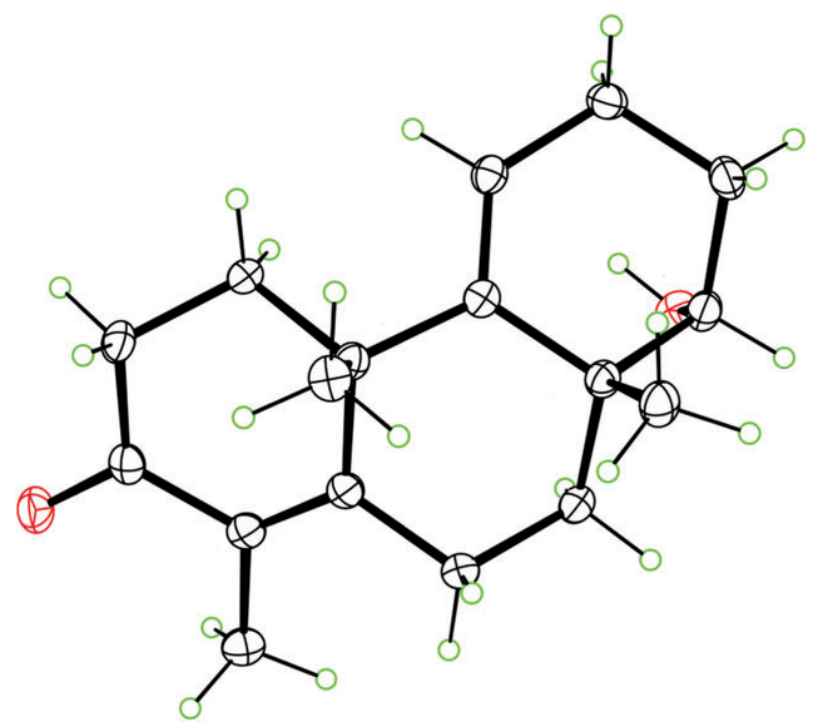

Figure 5. Crystal structure of compound $\mathbf{\pm 2 4}$ (ORTEP diagram), with $50 \%$ ellipsoids.

phenanthrene-like and expanded phenanthrene-like compounds respectively.

\subsection{Seedling bioassays}

Based on the results of the wheat coleoptile bioassay, decalins $\mathbf{1 9}$ to 22 were discarded. Only saturated phenanthrene-like (23 to 34) and expanded phenanthrene-like ( $\mathbf{3 5}$ to $\mathbf{4 3}$ ) compounds were selected for the seedling bioassay. The results are reported in the supporting information.
Generally, neither saturated phenanthrene-like nor expanded phenanthrene-like compounds show significant inhibitory activities on cress or lettuce. The most remarkable effects were obtained only at $1 \mathrm{mM}$ concentration in cress for the saturated phenanthrenes 24 [90\% inhibition of cress germination and significant inhibitions of root and shoot growth (a calculated IC ${ }_{50}$ value of 446 and $851 \mu \mathrm{M}$ respectively)], 36 [a calculated $\mathrm{IC}_{50}$ of $299 \mu \mathrm{M}$ (shoot length)] and 37 [a calculated $\mathrm{IC}_{50}$ of $479 \mu \mathrm{M}$ (root length)]. Significant activities were not found in lettuce, with the exception of compounds 35, 36 and $\mathbf{3 8}$ (expanded phenanthrenes), which showed moderate stimulation of shoot growth. The structure of expanded phenanthrenes resembles that of some of the plant hormones brassinosteroids, which induce stimulation of shoot growth, i.e. a seven-membered ring (an oxepane ring in the case of brassinosteroids) in an expanded phenanthrene backbone, a methyl C11a with identical angular orientation and a carbonyl system in the ring $A .{ }^{33}$ However, there is insufficient data to determine whether such similarities may contribute to the observed activities.

In spite of the lack of activity on these dicots, some compounds proved to be inhibitory against the weeds L. rigidum and E. crus-galli. The corresponding $I C_{50}$ values for root and shoot growth inhibitions, in cases where it was possible to calculate them, are given in Tables 1 to 3 . Root length was the most clearly affected parameter in L. rigidum, and the $\alpha, \beta$-unsaturated compound $\mathbf{2 4}$ was the most active (Table 1) of the saturated phenanthrene-like compounds, as it also inhibited germination and shoot growth. Compounds $\mathbf{2 5}$ and $\mathbf{2 6}$ also affect germination.

Expanded phenanthrene-like compounds reduced growth of L. rigidum $\mathrm{G}$., with shoot growth being the most inhibited parameter (Fig. 7). $I C_{50}$ values for both shoot and root growth are given in Table 2. The compounds that showed the strongest inhibition of shoot growth were $\mathbf{3 5}$ to $\mathbf{3 9}$, and compound $\mathbf{3 6}$ was the most

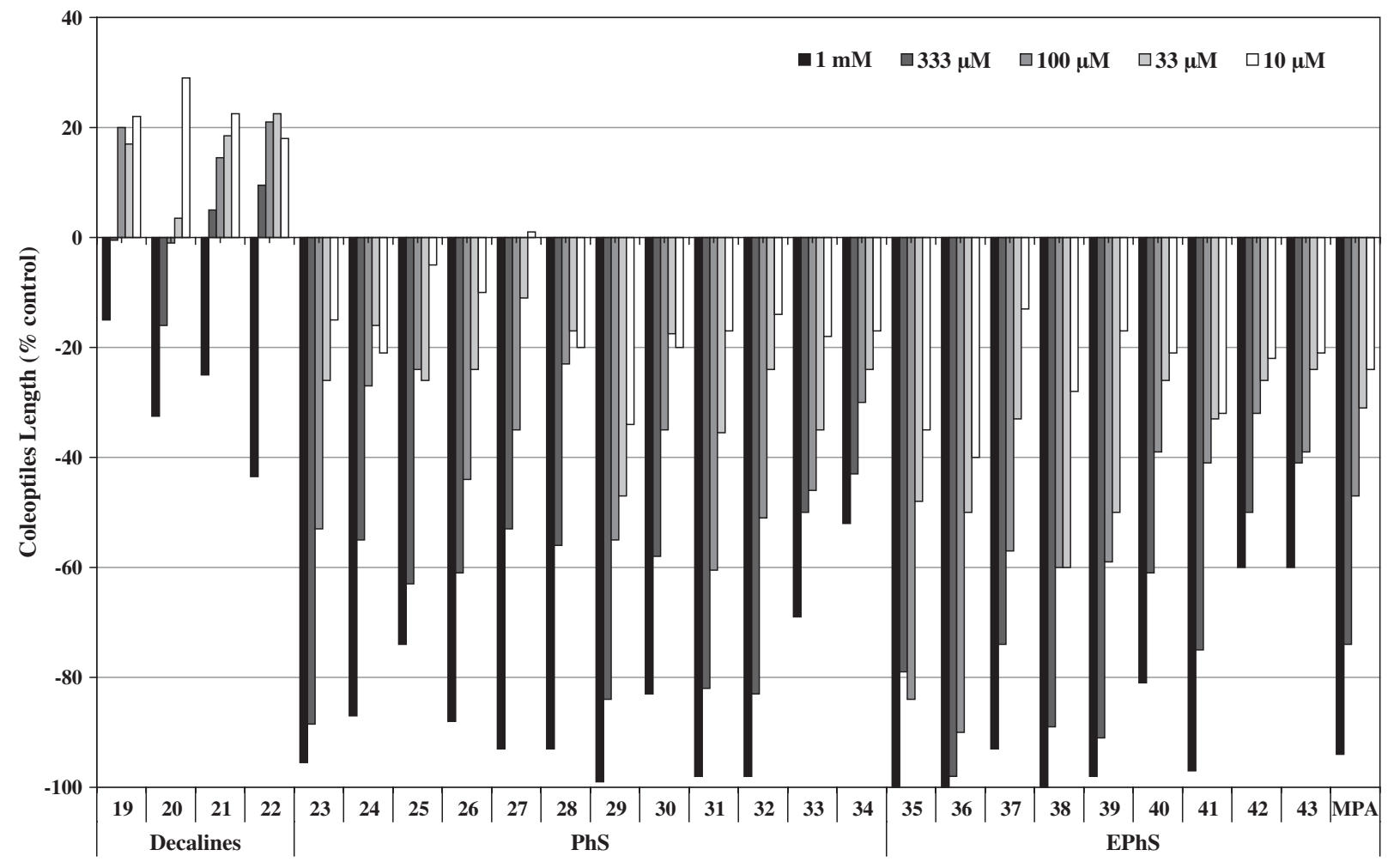

Figure 6. Effect of the compounds tested on wheat etiolated coleoptiles. 


\begin{tabular}{|c|c|c|c|c|c|}
\hline Compound & $\mathrm{IC}_{50}(\mu \mathrm{M})$ & $R^{2}$ & Compound & $\mathrm{IC}_{50}(\mu \mathrm{M})$ & $R^{2}$ \\
\hline 23 & 2725 & 0.9918 & 29 & 8641 & 0.8774 \\
\hline 24 & 446 & 0.9841 & 30 & 2097 & 0.9835 \\
\hline 25 & 778 & 0.9887 & 31 & 1371 & 0.9580 \\
\hline 26 & 2509 & 0.9935 & 32 & 15760 & 0.9767 \\
\hline 27 & 1573 & 0.9589 & 33 & 6394 & 0.9727 \\
\hline 28 & 880 & 0.9551 & 34 & 3092 & 0.9837 \\
\hline $\operatorname{Logran}^{\circledR}$ & 179 & 0.9527 & & & \\
\hline
\end{tabular}

Table 2. $I C_{50}$ values for root and shoot growth of $L$. rigidum in expanded phenanthrenes 35 to 43

\begin{tabular}{|lcccc|} 
Compound & $I_{50}$ root $(\mu \mathrm{M})$ & $R^{2}$ & $I_{50}$ shoot $(\mu \mathrm{M})$ & $R^{2}$ \\
\hline $\mathbf{3 5}$ & 1560 & 0.9659 & 1138 & 0.9644 \\
$\mathbf{3 6}$ & 1727 & 0.9828 & 785 & 0.9830 \\
$\mathbf{3 7}$ & 4272 & 0.9906 & 781 & 0.9651 \\
$\mathbf{3 8}$ & 2344 & 0.9970 & 1028 & 0.9852 \\
$\mathbf{3 9}$ & 1576 & 0.9964 & 1873 & 0.9793 \\
$\mathbf{4 0}$ & 1353 & 0.9937 & 2604 & 0.9893 \\
$\mathbf{4 1}$ & 1887 & 0.9826 & 2223 & 0.9960 \\
$\mathbf{4 2}$ & 1533 & 0.9783 & 2807 & 0.9846 \\
$\mathbf{4 3}$ & 6391 & 0.9806 & 5445 & 0.9800 \\
Logran $^{\circledR}$ & 179 & 0.9659 & 376 & 0.9201 \\
\hline
\end{tabular}

Table 3. $\quad \mathrm{IC}_{50}$ values for root growth activity of E. crus-galli in saturated phenanthrenes $23-34$

\begin{tabular}{|lccccc|} 
Compound & $\mathrm{IC}_{50}(\mu \mathrm{M})$ & $R^{2}$ & Compound & $\mathrm{I} \mathrm{C}_{50}(\mu \mathrm{M})$ & $R^{2}$ \\
\hline $\mathbf{2 3}$ & 650 & 0.9891 & $\mathbf{2 9}$ & 1391 & 0.9652 \\
$\mathbf{2 4}$ & 141 & 0.9842 & $\mathbf{3 0}$ & 427 & 0.8766 \\
$\mathbf{2 5}$ & 1070 & 0.9520 & $\mathbf{3 1}$ & 146 & 0.8950 \\
$\mathbf{2 6}$ & 653 & 0.9593 & $\mathbf{3 2}$ & 83 & 0.9391 \\
$\mathbf{2 7}$ & 140 & 0.9679 & $\mathbf{3 3}$ & 120 & 0.9033 \\
$\mathbf{2 8}$ & 121 & 0.9916 & $\mathbf{3 4}$ & 2479 & $0.7345^{*}$ \\
Logran $^{\circledR}$ & 1230 & 0.8572 & Cotanil $^{\circledR}$ & 116 & 0.9632 \\
\hline
\end{tabular}

*Value calculated although experimental data do not conform to a dose-response curve.

active. Compounds 35, 39, 40 and $\mathbf{4 2}$ were the most active in reducing root growth, while $\mathbf{3 5}$ and $\mathbf{3 6}$ were the only ones affecting germination significantly.

E. crus-galli proved to be more sensitive to the effect of both saturated phenanthrene-like and expanded phenanthrene-like compounds. More intense effects were found on root growth (Table 3), and compounds $\mathbf{2 4 ,} \mathbf{2 7}$ and $\mathbf{2 8}$ were the most active (an $\mathrm{IC}_{50}$ value of around $100 \mu \mathrm{M}$ ) of the saturated phenanthrene-like series. Expanded phenanthrene-like compounds were much more active (Table 4) and generally showed $\mathrm{IC}_{50}$ values that were almost one order of magnitude lower for root growth when compared with the other set of compounds; significant to intense activities on shoot growth were also found. Compounds 37, 38 and $\mathbf{4 2}$ showed remarkable inhibition of root growth $\left(\mathrm{IC}_{50}\right.$ values of 24,14 and 7 $\mu \mathrm{M}$ respectively).
As a general trend, a greater selectivity in the effect of these compounds on the two weeds (monocot and dicot) was observed, and also with respect to dicot crops. These effects warrant consideration for the control of E. crus-galli in dicot crops, where they have little or no effect, and in monocot crops similar to L. rigidum, where their inhibitory activities are lower.

\subsection{SAR studies}

The SAR studies will be discussed mainly by considering the data obtained on E. crus-galli, as it proved to be the most sensitive species (Tables 3 and 4; Fig. 8). Comparisons will also be made with the results obtained on wheat coleoptiles, as this is the most complete set of data.

At first sight, there was a clear difference between decalins and the rest of the compounds tested when they were assayed on wheat coleoptiles. An extensive study was conducted between different molecular descriptors, and, besides the difference between the molecular volumes, the only clear qualitative relation was found between lipophilia (calculated $\log P$ ) and activity (Fig. 9). However, quantitative correlations could not be found.

\subsubsection{Saturated phenanthrenes (sPhs)}

The sPhs affected mainly root growth of E. crus-galli. The most active compounds were $32\left(\mathrm{IC}_{50}=83 \mu \mathrm{M}\right)$, followed by 24, 27, 28, 31 and $33\left(100<\mathrm{IC}_{50}<150 \mu \mathrm{M}\right)$ (Table 3$)$. The compounds having the lowest activities by far were 29 and $\mathbf{3 4}\left(\mathrm{IC}_{50}>1000 \mu \mathrm{M}\right)$. All compounds (23 to $\mathbf{3 4}$ ) had oxygenated substituents in the same positions ( $C 2$ and $C 8$ ) at rings $A$ and $C$ - carbonyl, hydroxyl, ether or modified carbonyl (ethylene glycol) groups. The accessibility to these two groups seemed to be important for activity. Modifications affecting the accessibility to these functional groups, either as a methoxyethyl ether (OMOM, 29, IC $\left.{ }_{50}=1391 \mu \mathrm{M}\right)$ or vicinal (C7) methyl group (34, IC $50=2479 \mu \mathrm{M})$, had a negative effect on activity.

Compounds 31, 32 and $\mathbf{3 3}$ are a set of related compounds that were among the most active in the saturated phenanthrene series ( $\left(C_{50}\right.$ values of 146,83 and $120 \mu \mathrm{M}$ respectively) (Table 3 ). In this group, the carbonyl moiety at ring $C$ was either free (31) or modified as an ethylene glycol derivative (32 and 33). Ethylene glycol protecting groups are sensitive to mildly acidic $\mathrm{pH}$ conditions over long periods of time, and such conditions occurred in the bioassay ( 5 days). ${ }^{34,35}$ Consequently, similar activities for the compounds might be expected. It is important to note also that compounds $\mathbf{3 3}$ and $\mathbf{2 8}$, both having a carbonyl group in ring $C$, showed the same activity $\left(\mathrm{IC}_{50} \sim 120 \mu \mathrm{M}\right)$. The introduction of a methyl group in ring $C$ vicinal to the carbonyl group induced a marked decrease in activity, as previously stated.

Compound 24, which has an $\alpha, \beta$-unsaturated carbonyl system and a hydroxyl group at C8 with opposite orientation to the rest of the series, was one of the active compounds. It seemed that the stereochemistry of the hydroxyl group influenced the activity of the unsaturated system; $c f$. the $I C_{50}$ values of compounds $24\left(\mathrm{CBS}^{*}\right)$ and 23 (C8R) (141 and $650 \mu \mathrm{M}$ respectively) (Table 3 ). The decrease in activity observed when the double bond of the $\alpha, \beta$-unsaturated carbonyl system was not present can be seen by comparing the values for compounds $23\left(\mathrm{IC}_{50}=650 \mu \mathrm{M}\right)$ and $\mathbf{2 5}\left(\mathrm{IC}_{50}=1070 \mu \mathrm{M}\right)$. The activity recovered when the double bond at the $C$ ring was not present (compound 26, $I C_{50}=653 \mu \mathrm{M}$ ). However, the reasons for this behaviour cannot be determined without knowing the site of action of these compounds. 

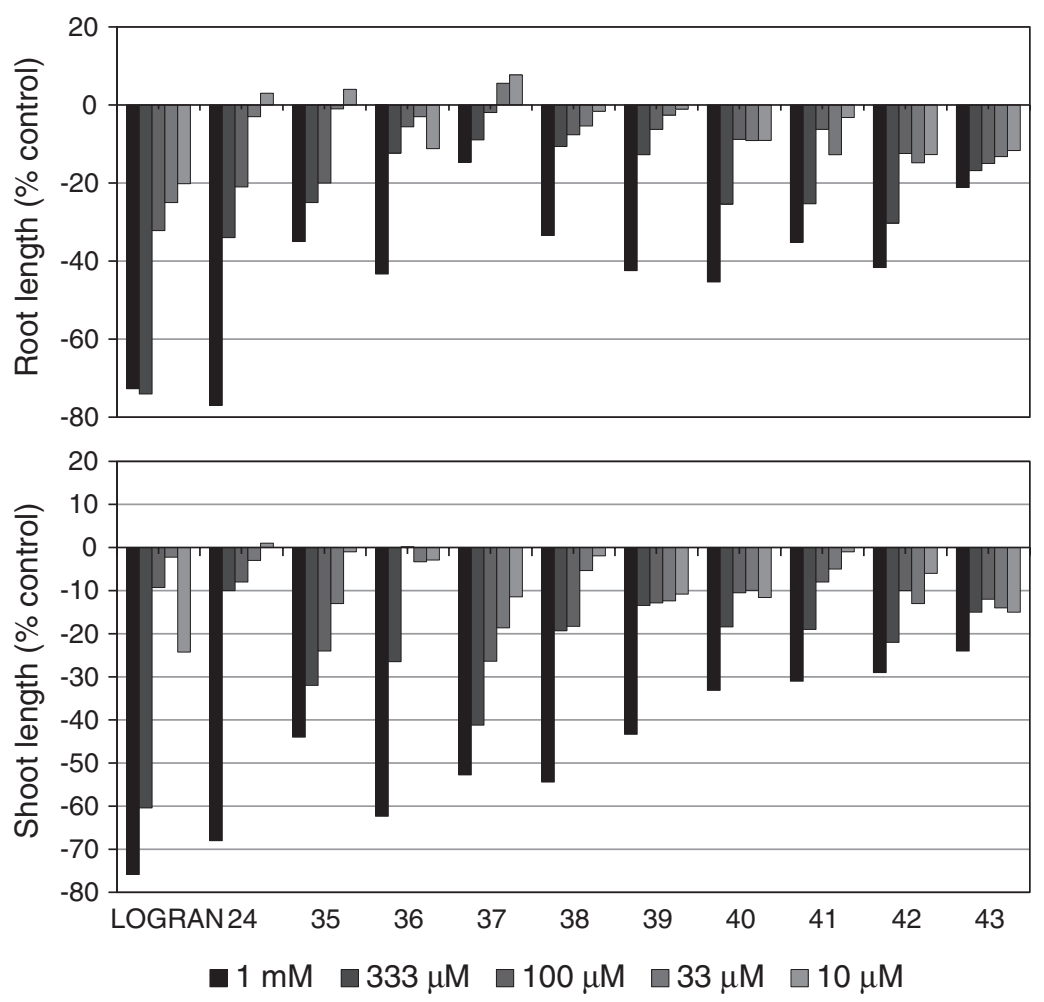

Figure 7. Effect of compounds 24 and expanded phenanthrenes 35-43 on L. rigidum G.

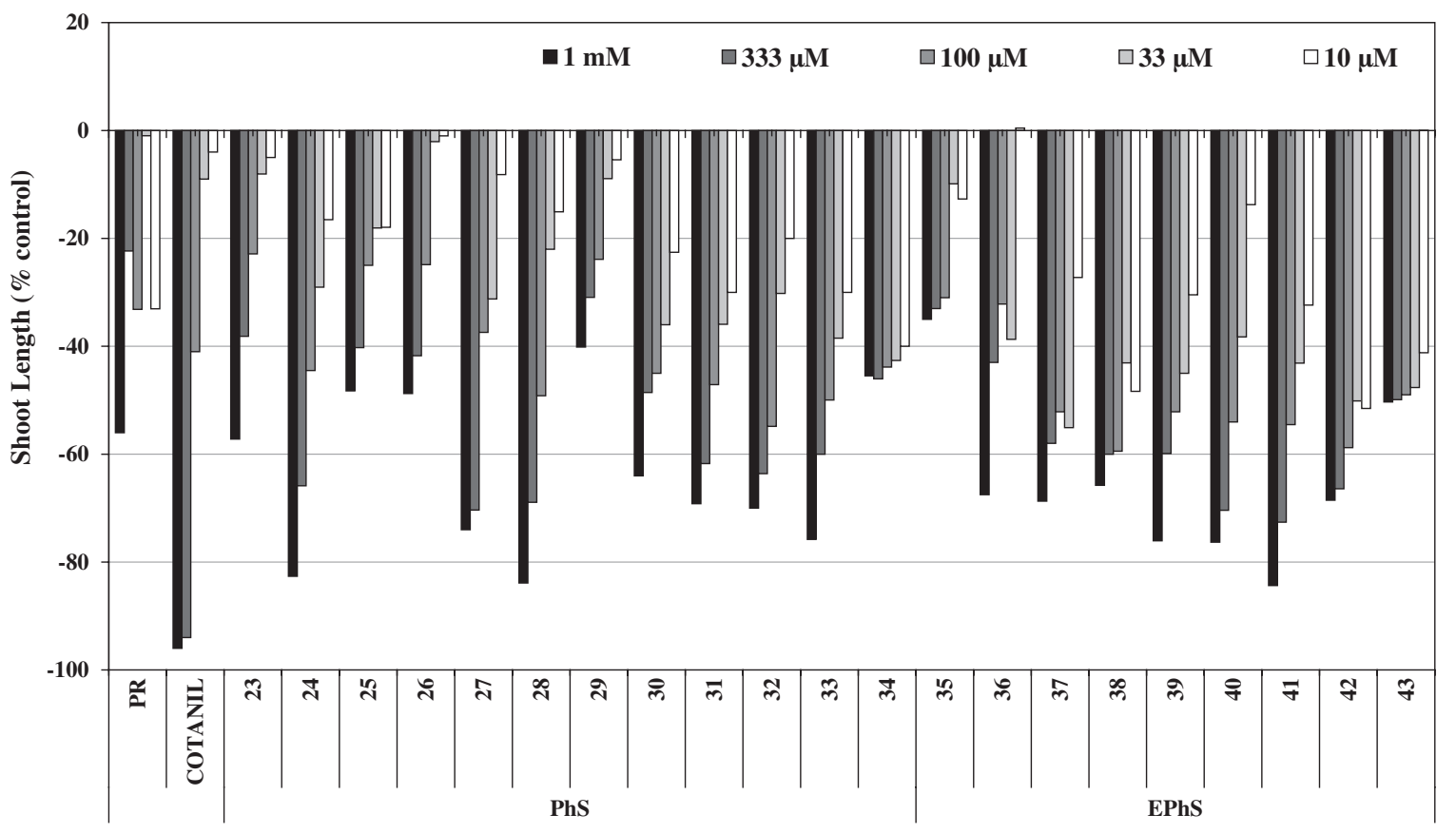

Figure 8. Inhibitory effect on shoot and root growth of E. crus-galli L.

\subsubsection{Expanded phenanthrenes (ePhs)}

The behaviour of this set of compounds ( 35 to 43 ) was quite different from that of the saturated phenanthrenes $\mathbf{2 3}$ to $\mathbf{3 4}$. It should first be noted that ePhs were generally more active than sPhs, as evidenced by comparison of the IC $C_{50}$ values in Tables 3 and 4 .

Another trend is that compounds containing an $\alpha, \beta$-unsaturated carbonyl system in ring $A$ (compounds 35 and 36) were among the least active of the entire series. However, steric hindrance of the double bond in $\mathbf{3 5}$ and $\mathbf{3 6}$ is no greater than in $\mathbf{2 3}$ and $\mathbf{2 4}$ (Fig. 10). In fact, comparison of the activities of $23\left(\mathrm{IC}_{50}=650 \mu \mathrm{M}\right)$ and $36\left(\mathrm{IC}_{50}=425 \mu \mathrm{M}\right)$ showed them to be in the same range. The behaviour described above is opposite to that of the previous sPhs series, in which $\alpha, \beta$-unsaturated carbonyl compound $\mathbf{2 4}$ is among the most active. Furthermore, comparison of these results with those obtained with coleoptiles shows that all compounds with an $\alpha, \beta$-unsaturated carbonyl system in ring $\mathrm{A}$ are among the most 


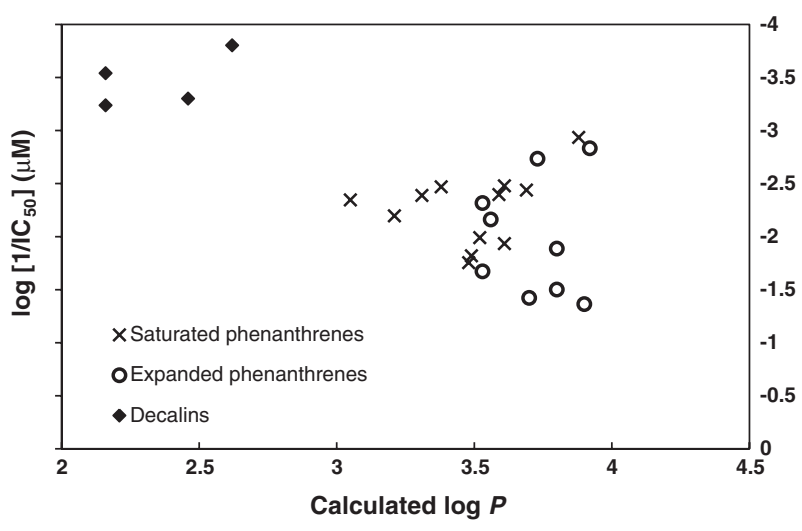

Figure 9. Calculated $\log P$ versus $I C_{50}$ in the wheat coleoptile bioassay.

Table 4. IC $\mathrm{C}_{50}$ values for root and shoot growth of E. crus-galli (L.) in expanded phenanthrenes $\mathbf{3 5}$ to $\mathbf{4 3}$

\begin{tabular}{|lcccc|} 
Compound & $\mathrm{IC}_{50}$ root $(\mu \mathrm{M})$ & $R^{2}$ & $\mathrm{I} \mathrm{C}_{50}$ shoot $(\mu \mathrm{M})$ & $R^{2}$ \\
\hline $\mathbf{3 5}$ & 1979 & 0.9251 & 2445 & 0.9316 \\
$\mathbf{3 6}$ & 425 & 0.8907 & 564 & 0.9870 \\
$\mathbf{3 7}$ & 24 & 0.8363 & 1039 & 0.8136 \\
$\mathbf{3 8}$ & 14 & 0.8096 & 620 & 0.8848 \\
$\mathbf{3 9}$ & 61 & 0.8847 & 413 & 0.9142 \\
$\mathbf{4 0}$ & 66 & 0.9664 & 591 & 0.9110 \\
$\mathbf{4 1}$ & 57 & 0.9455 & 419 & 0.9710 \\
$\mathbf{4 2}$ & 7 & 0.8241 & 850 & 0.9246 \\
$\mathbf{4 3}$ & 1729 & $0.6872^{*}$ & 15600 & $0.7783^{*}$ \\
Cotanil $^{\circledR}$ & 116 & 0.9632 & 208 & 0.9322 \\
Logran $^{\circledR}$ & 1230 & 0.8572 & 1361 & 0.9593 \\
\hline
\end{tabular}

*Value calculated although experimental data do not conform to a dose-response curve.
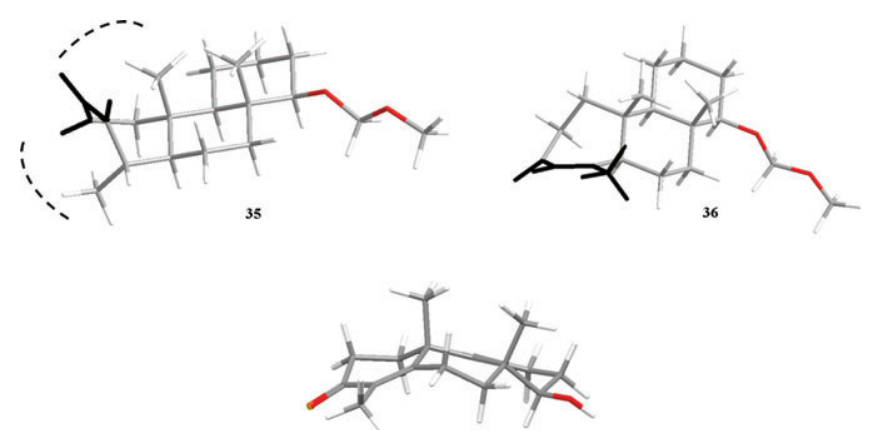

Figure 10. $\alpha, \beta$-Unsaturated carbonyl system accessibility in compounds 35 and 36.

active. This trend indicates that different modes of action and/or molecular targets with different structural requirements may be associated with E. crus-galli and the other monocots assayed (L. rigidum and wheat in the coleoptile bioassay).

Oxidation of the hydroxyy group in ring $C$ led to a clear increase in the activity on root growth of E. crus-galli. The resulting compound (42) had the highest activity $\left(\mathrm{IC}_{50}=7 \mu \mathrm{M}\right)$ when compared with the compound with the free hydroxy group $\left(\mathbf{4 1}, I_{50}=57 \mu \mathrm{M}\right)$ (Table 4). The same trend was observed for $L$. rigidum (Table 2). Surprisingly, the trend is opposite in the wheat coleoptile bioassay, where the carbonyl derivative at ring $C$ was more active than the compounds with a free hydroxyl group (Table 1). Compound 43, which also had the hydroxy group oxidised, turned inactive when a methyl group was added to ring $C$, as stated above.

In a similar way to compound $\mathbf{3 4}$, the introduction of a methyl substituent close to the carbonyl group led to a dramatic loss of activity [compound 43, IC 50 (root) $=1729 \mu \mathrm{M}$ ]. This behaviour was not as clear in the wheat coleoptile and L. rigidum bioassays, but the trend was still apparent.

Regarding the modification of the carbonyl group at ring $A$ to a 1,3-dioxolane derivative (compounds $\mathbf{3 9}$ and $\mathbf{4 0}$ versus compounds 41 and 42), once again differences could not be observed in their activities $\left[\mathbf{4 0}, I C_{50}(\right.$ root $)=66 \mu \mathrm{M}, I C_{50}$ (shoot) $=591 \mu \mathrm{M} ; 41$, $I C_{50}$ (root) $=57 \mu \mathrm{M}, I C_{50}$ (shoot) $\left.=419 \mu \mathrm{M}\right]$ (Table 5), which is probably due to cleavage of the cyclic acetal moiety. This result is similar to that observed for the previously discussed phenanthrene-like series.

A cluster analysis performed on the data for root growth activity on E. crus-galli supported the previous observations and split the compounds into two well-differentiated groups: G1 for compounds with high and moderate activity and G2 for compounds with low activity. G1 was in turn divided into two subgroups: G1a (for compounds with the highest activity) and G1b (for compounds exhibiting moderate effects) (Fig. 11).

G1a contained most of the ePhs, thus confirming the order of activity observed. This group also included the herbicide Cotanil, which is specifically recommended for this weed, while Logran was grouped with the non-active compounds. Compounds $\mathbf{3 8}$, 41 and 42 were also closely grouped, as would be expected, given that the 1,3-dioxolane derivative $\mathbf{4 2}$ is unstable under mildly acid conditions; none of these ePhs had $\alpha, \beta$-unsaturated carbonyl systems, as mentioned previously.

Most Phs were grouped in categories G1b or G2. This finding is consistent with the lower activity shown in general by these groups of compounds on E. crus-galli and supports the idea of differentiated targets or modes of actions for Phs and ePhs. Only Phs that were structurally very similar to ePhs were grouped closer. Thus, the subgroup G1a includes the pairs 33 (Phs) and 42 (ePhs), both with a carbonyl group at ring $C$ and the other carbonyl modified as a cyclic acetal. This could be indicative of the importance of structural similarities in ring $C$.

A similar analysis was also performed on data obtained with wheat coleoptiles, and similar trends were identified (data not shown). This analysis separated the decalin group and divided the rest of the compounds into two subgroups: one with high activity and the other with moderate activity. As for E. crus-galli, compounds in the more active group were essentially expanded phenanthrenes. However, in this case the expanded phenanthrenes with a cyclic acetal unit instead of the carbonyl group were not grouped together. A closer view of the $I C_{50}$ values showed that these compounds were less active: compound $\mathbf{3 8}$ (with a carbonyl group in ring $A$ ) had an $\mathrm{IC}_{50}$ value of $32 \mu \mathrm{M}$, whereas compounds 41 and $\mathbf{4 2}$ (with the carbonyl group modified as an acetal) showed lower activities ( $\mathrm{IC}_{50}$ of 145 and $543 \mu \mathrm{M}$ respectively). In this case, the bioassay lasted for only $24 \mathrm{~h}$, and this was probably insufficient time for cleavage of the protective group.

Finally, it is important to highlight the high specificity shown by these compounds on E. crus-galli in comparison with L. rigidum and the lettuce and cress crop seeds. The selectivity index $\left(\mathrm{SI}_{50}\right)$ was defined as the $\mathrm{IC}_{50}$ (root) ratio of L. rigidum to E. crus-galli, and the values obtained are shown in Fig. 12. The highest selectivity was shown by compounds $32\left(\mathrm{SI}_{50}=189\right), 37\left(\mathrm{SI}_{50}=179\right), 38$ 


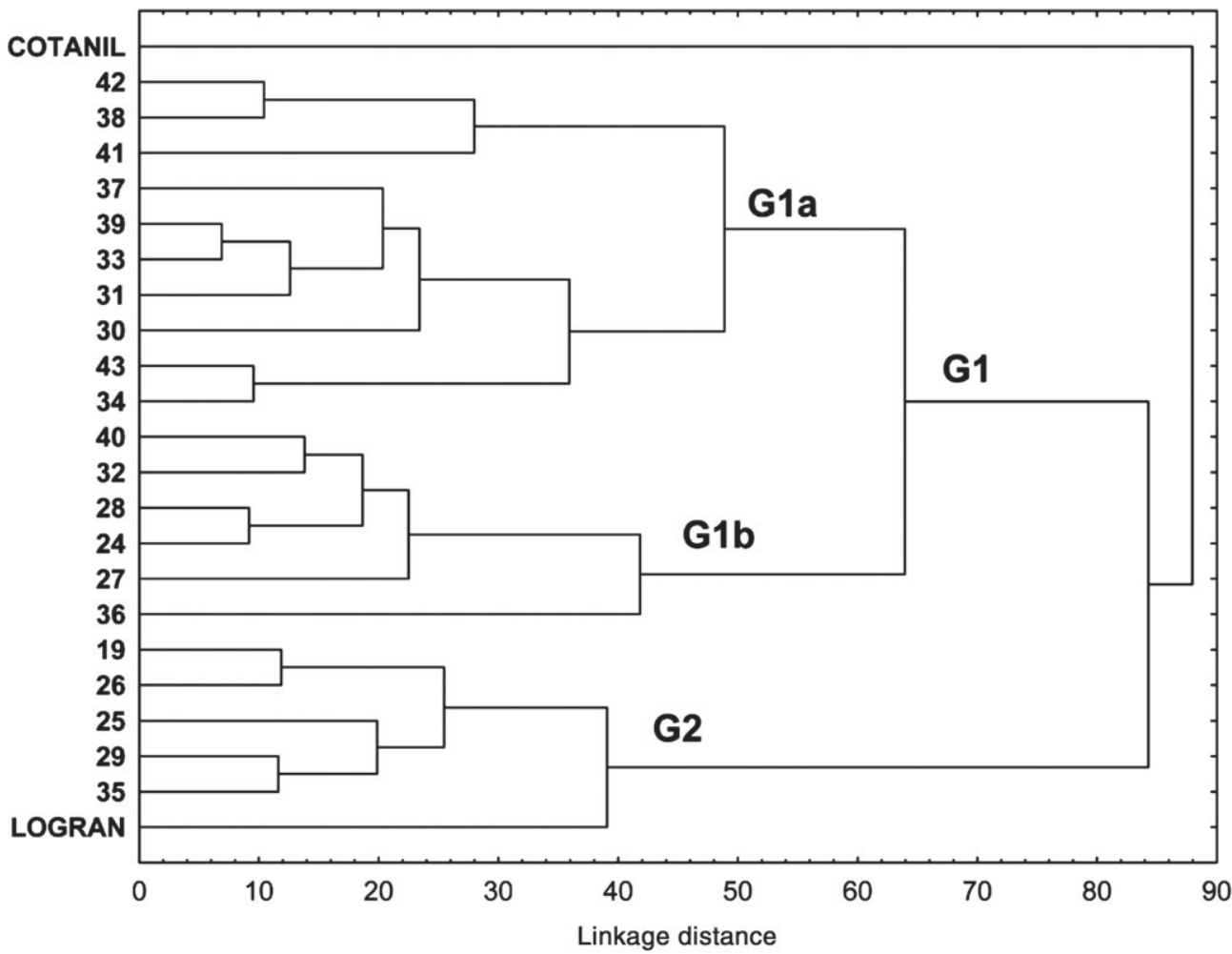

Figure 11. Cluster analysis obtained from root growth data for E. crus-galli L.

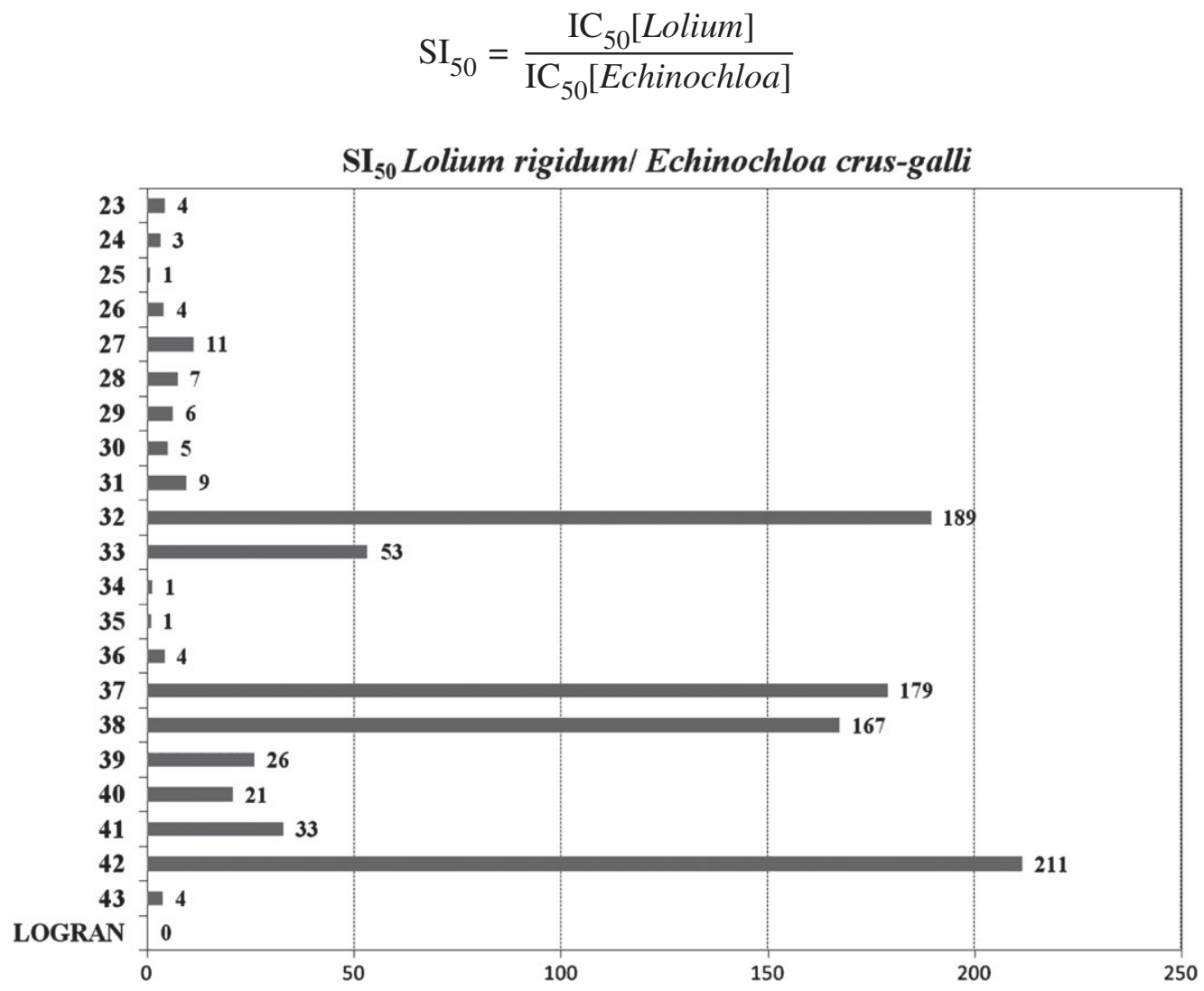

Figure 12. Selectivity of the tested compounds against E. crus-galli: $\mathrm{SI}_{50}=\frac{\mathrm{IC}_{50}[\text { Lolium }]}{\mathrm{I}_{50}[\text { Echinochloa }]}$. 
<smiles>C1CCC2CCC3CCCCC3C2CC1</smiles>

Expanded phenanthrene-like structures

Phenanthrene-like structures<smiles>CCC1CCCC(=O)C(C)C1C</smiles><smiles>CC1CC=CC(=O)[C@H](C)C1C</smiles><smiles>CC1CCC(=O)CC(C)C1C</smiles>

38<smiles>CC1CCC(=O)C=C([18O])C1C</smiles><smiles>CC1CCC(=O)C(C)(C)C1C</smiles>

30, 31

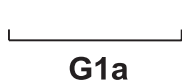<smiles>CCC1CCC(=O)C(C)=C1C</smiles>

23<smiles>CC1CCC(=O)[C@H](C)C1C</smiles>

25,26
Figure 13. Summary of SAR conclusions.

$\left(\mathrm{SI}_{50}=167\right)$ and $42\left(\mathrm{SI}_{50}=211\right)$, which also exhibited the highest activities $\left(\mathrm{IC}_{50}<100 \mu \mathrm{M}\right)$. Such values represent a difference of at least two orders of magnitude in the action of these compounds between the two target species. As the behaviour of L. rigidum can be taken in the first instance as representative of monocot crops, the possibility of using these compounds as leads for the development of selective herbicides to control E. crus-galli in monocot crops is clear.

\section{CONCLUSIONS}

In summary, based on the observations discussed above, some conclusions can be drawn at the structural level specifically for $E$. crus-galli (Fig. 13):

1. Compounds with ePhs are more active on E. crus-galli than compounds with sPhs. Six out of the nine ePhs compounds assayed are grouped in $\mathrm{G} 1 \mathrm{a}$, which comprises those compounds with the highest activities.

2. $\alpha, \beta$-Unsaturated carbonyl systems in ePhs do not seem to be more active in E. crus-galli than their corresponding saturated systems, as can be observed by comparing the pairs 35/37 and $36 / 38$. The same behaviour can be seen for sPhs on comparing the pair $\mathbf{2 3 / 2 5}$. However, this trend is opposite to that found for $L$. rigidum and in the coleoptile bioassay. This behaviour could be a sign of the specificity of action of these compounds towards E. crus-galli.

3. In the sPhs, the presence of a ketone or hydroxyl accessible groups in rings $A$ and $C$ seems to play an important role in activity. Irreversible modifications of these groups results in a loss of activity. This does not seem to occur in ePhs. Different molecular targets or modes of action for each series could explain this behaviour.

4. Within compounds with sPhs, those that contain a gem-dimethyl group in ring $A$ are more active than the rest of the series, and they are grouped mainly in the $\mathrm{G} 1$ subgroup.

In general, compounds with an expanded phenanthrene-like skeleton were more active (by about one order of magnitude) than those with a phenanthrene-like skeleton. These compounds had a high selectivity on Echinochloa crus-galli growth, as compared with the activity observed on Lolium rigidum, and a residual activity on dicot crop seeds. This behaviour makes these compounds good candidates as leads for the development of selective herbicides on these crops.

\section{ACKNOWLEDGEMENTS}

This paper was supported by the Consejería de Innovación, Ciencia y Empresa, Junta de Andalucía (Project P10-AGR-5822).

\section{SUPPORTING INFORMATION}

Supporting information may be found in the online version of this article.

\section{REFERENCES}

1 Cantrell CL, Dayan FE and Duke SO, Natural products as sources for new pesticides. J Nat Prod 75(6):1231 - 1242 (2012).

2 Wright VF, Vesonder RF and Ceigler A, Mycotoxins and other fungal metabolites as insecticides, in Microbial and Viral Pesticides. Marcel Dekker, New York, NY, pp. 559-587 (1982).

3 Moya P, Castillo M, Primo-Yufera E, Couillaud F, Martinez-Manez R, Garcera M-D et al., Brevioxime: a new juvenile hormone biosynthesis inhibitor isolated from Penicillium brevicompactum. J Org Chem 62(24):8544-8545 (1997).

4 Moya P, Cantín Á, Castillo M-A, Primo J, Miranda MA and Primo-Yúfera $\mathrm{E}$, Isolation, structural assignment, and synthesis of $\mathrm{N}$-(2-methyl-3-oxodecanoyl)-2-pyrroline, a new natural product from Penicillium brevicompactum with in vivo anti-juvenile hormone activity. J Org Chem 63(23):8530-8535 (1998).

5 Cantin A, Moya P, Castillo M-A, Primo J, Miranda $M A$ and Primo-Yufera $E$, Isolation and synthesis of $\mathrm{N}$-(2-methyl-3-oxodec-8-enoyl)-2-pyrroline and 2-(hept-5-enyl)-3methyl-4-oxo-6,7,8,8a-tetrahydro-4H-pyrrolo[2,1-b]-1,3-oxazine. Two new fungal metabolites with in-vivo anti-juvenile-hormone and insecticidal activity. Eur J Org Chem 1(1):221 - 226 (1999).

6 Cantin A, Lopez-Gresa MP, Gonzalez MC, Moya P, Miranda MA, Primo $J$ et al., Novel inhibitors of the mitochondrial respiratory chain: oximes and pyrrolines isolated from Penicillium brevicompactum and synthetic analogues. J Agric Food Chem 53(21):8296-8301 (2005).

7 Kusano M, Sotoma G and Kimura Y, Brevicompanins A and B: new plant growth regulators produced by the fungus, Penicillium brevicompactum. J Chem Soc Perkin Trans 1 36(1):97-101 (2001).

8 Kimura Y, Sawada A, Kuramata M, Kusano M, Fujioka S, Kawano T et al., Brevicompanin C, cyclo-(D-Ile-L-Trp), and cyclo-(D-Leu-L-Trp), plant growth regulators from Penicillium brevicompactum. J Nat Prod 68(2):237-239 (2005).

9 Takahashi M, Tanazawa K and Takahashi S, Adenophostins, newly discovered metabolites of Penicillium brevicompactum, act as potent agonists of the inositol 1,4,5-trisphosphate receptor. J Biol Chem 269(1):369-372 (1994).

10 Murphy CT, Riley AM, Lindley CJ, Jenkins DJ, Westwick J and Potter BVL, Structural analogs of D-myo-inositol-1,4,5-trisphosphate and adenophostin A: recognition by cerebellar and platelet inositol-1, 4,5-trisphosphate receptors. Mol Pharmacol 52(4):741 - 748 (1997).

11 Macias FA, Varela RM, Simonet AM, Cutler HG, Cutler SJ, Dugan FM et al., Novel bioactive breviane spiroditerpenoids from Penicillium brevicompactum Dierckx. J Org Chem 65(26):9039-9046 (2000). 
12 Macias FA, Varela RM, Simonet AM, Cutler HG, Cutler SJ, Ross SA et al., Allelochemicals from New Zealand fungi - (+)-Brevione A. The first member of a novel family of bioactive spiroditerpenoids isolated from Penicillium brevicompactum Dierckx. Tetrahedr Lett 41(15): $2683-2686$ (2000).

13 Li Y, Ye D, Chen X, Lu X, Shao Z, Zhang H et al., Breviane spiroditerpenoids from an extreme-tolerant Penicillium sp. isolated from a deep sea sediment sample. J Nat Prod 72(5):912-916 (2009).

14 Li Y, Ye D, Shao Z, Cui C and Che Y, A sterol and spiroditerpenoids from a Penicillium sp. isolated from a deep sea sediment sample. Mar Drugs 10(2):497-508 (2012).

15 Gerwick WH and Fenical W, Ichthyotoxic and cytotoxic metabolites of the tropical brown alga Stypopodium zonale (Lamouroux) Papenfuss. J Org Chem 46(1):22-27 (1981).

16 Sunazuka $\mathrm{T}$ and Omura $\mathrm{S}$, Total synthesis of $\alpha$-pyrone meroterpenoids, novel bioactive microbial metabolites. Chem Rev 105(12): 4559-4580 (2005)

17 Handa M, Sunazuka T, Nagai K, Kimura R, Otoguro K, Harigaya Y et al., Determination of absolute stereochemistries of arisugacin $\mathrm{F}$ and territrem B, novel acetylcholinesterase inhibitors. J Antibiot 54(4):386-391 (2001).

18 Macias FA, Carrera C and Galindo JCG, Brevianes revisited. Chem Rev 114(5):2717-2732 (2014).

19 Macias FA, Carrera C, Chinchilla N, Fronczek FR and Galindo JCG, Synthesis of the western half of breviones C, D, F and G. Tetrahedron 66:4125-4132 (2010).

20 Takikawa H, Imamura $\mathrm{Y}$ and Sasaki M, Synthesis and absolute configuration of brevione $\mathrm{B}$, an allelochemical isolated from Penicillium sp. Tetrahedron 62(1):39-48 (2005).

21 Yokoe H, Mitsuhashi C, Matsuoka Y, Yoshimura T, Yoshida M and Shishido K, Enantiocontrolled total syntheses of breviones A, B, and C. J Am Chem Soc 133(23):8854-8857 (2011).

22 Honda T, Favaloro FG, Jr, Janosik T, Honda $Y$, Suh N, Sporn MB et al., Efficient synthesis of (-)- and (+)-tricyclic compounds with enone functionalities in rings $A$ and $C$. A novel class of orally active anti-inflammatory and cancer chemopreventive agents. Org Biomol Chem 1(24):4384-4391 (2003).

23 PRISM v.4.0. GraphPad Software Inc., San Diego, CA (2003).

24 Sander T, OSIRIS Property Explorer. Actelion, Allschwil, Switzerland (2001).

25 Chou JT and Jurs PC, Computer-assisted computation of partition coefficients from molecular structures using fragment constants. $J$ Chem Inf Comput Sci 19(3):172-178 (1979).

26 Hancock CR, Barlow HWB and Lacey HJ, The East Malling coleoptile straight growth test method. J Exp Bot 15(1):166-176 (1964).

27 Nitsch JP and Nitsch C, Studies on the growth of coleoptile and first internode sections. A new, sensitive, straight-growth test for auxins. Plant Physiol 31(2):94-111 (1956).

28 Martín Andrés A and Luna del Castillo JD, Bioestadística para las Ciencias de la Salud. Norma, Madrid, Spain (1990).

29 Bentley R, Mycophenolic acid: a one hundred year odyssey from antibiotic to immunosuppressant. Chem Rev 100(10):3801-3825 (2000).

30 Kaur R, Klichko V and Margolis D, Ex vivo modeling of the effects of mycophenolic acid on HIV infection: considerations for antiviral therapy. AIDS Res Hum Retroviruses 21(2):116-124 (2005).

31 Castellano D, Macías FA, Castellano M and Cambronero RM, FITOMED (automated system for measurement of variable lengths). Spanish Patent P9901565 (1999).

32 Statistica for Windows 5.0. Statsoft Inc., Tulsa, OK (1984-1995).

33 Steffens GL, US Department of Agriculture Brassins Project: 1970-1980, in Brassinosteroids. American Chemical Society, Washington, DC, pp. 2-17 (1991).

34 Juliá-Hernández F, Arcas A and Vicente J, Pd(II)-catalyzed deprotection of acetals and ketals containing acid sensitive functional groups. Tetrahedr Lett 55(6):1141-1144 (2014).

35 Wuts PGM and Greene TW, Greene's Protective Groups in Organic Synthesis, 4th edition. John Wiley \& Sons, Inc., New York, NY (2006). 